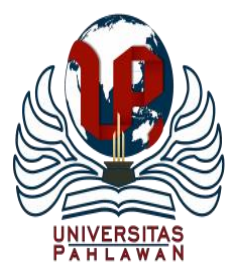

Jurnal Abdidas Volume 2 Nomor 3 Tahun 2021 Halaman 597-602

JURNAL ABDIDAS

http://abdidas.org/index.php/abdidas

\title{
Peningkatan Kualitas SDM Melalui Pelatihan Penggunaan Teknologi Informasi di Desa Air Anyir
}

\author{
Lili Indah Sari ${ }^{1 \bowtie}$, Wishnu Aribowo Probonegoro ${ }^{2}$, Supardi $^{3}$, Parlia Romadiana ${ }^{4}$ \\ Manajemen Informatika, Fakultas Teknologi Informasi, ISB Atma Luhur, Indonesia, \\ Sistem Informasi, Fakultas Teknologi Informasi, ISB Atma Luhur, Indonesia ${ }^{2,3}$ \\ E-mail: 1ilie@ atmaluhur.ac.id ${ }^{1}{ }^{\text {wishnuap77@ atmaluhur.ac.id }}{ }^{2}$, supardi@ atmaluhur.ac.id ${ }^{3}$ \\ parliaromadiana@atmaluhur.ac.id ${ }^{4}$
}

\begin{abstract}
Abstrak
Desa Air Anyir merupakan salah satu desa yang berada di Kecamatan Merawang, Kabupaten Bangka, Provinsi Kepulauan Bangka Belitung. Masih minimnya kemampuan dan skill teknologi informasi yang dimiliki oleh masyarakat, khususnya di tingkat remaja. Peningkatan kualitas Sumber Daya Manusia (SDM) sebaiknya dimulai sejak dini, (tingkat remaja) dapat berpengaruh pada daya saing individu itu sendiri agar bisa berkompetensi dan bersaing di era globalisasi dan digitalisasi ini. Untuk meningkatkan SDM yang ada di Desa Air Anyir perlu dilakukan pelatihan teknologi informasi guna memberikan kemampuan dalam penguasaan TI serta adanya kolaborasi dan kerja sama dari semua pihak. Metode pelaksanaan kegiatan pengabdian kepada masyarakat adalah ceramah, tanya jawab, praktik langsung. Sedangkan sasaran adalah tingkat remaja yang ingin memaksimalkan kemampuan komputer serta kemampuan teknologi informasi yang lain seperti pembuatan dan penggunaan email. Hasil dari pengabdian masyarakat ini yaitu: peserta memahami, mengerti dan memanfaatkan kemajuan teknologi informasi pemanfaatan handphone membuat dan menggunakan email pribadi. Email ini nantinya bisa digunakan untuk mendaftarsekolah, baik di tingkat SMA ataupun tingkat perguruan tinggi. Kegiatan ini cukup berhasil karena adanya jaringan internet yang memadai, yaitu diberikan akses Wi-Fi desa.
\end{abstract}

Kata kunci: Desa Air Anyir, kemampuan teknologi informasi, peningkatan SDM, email

\section{Abstract}

Air Anyir Village is one of the villages located in Merawang sub-district, Bangka district, Bangka Belitung Islands province. There is still a lack of information technology capabilities and skills possessed by the community, especially at the youth level. Improving the quality of Human Resources (HR) should start early, (adolescent level) can affect the competitiveness of the individual himself in order to be competent and competitive in this era of globalization and digitalization. To improve the existing human resources in the village of Air Anyir, it is necessary to conduct information technology training to provide the ability to master IT as well as collaboration and cooperation from all parties. The method of implementing community service activities is lecture, question and answer, direct practice. While the target is the level of teenagers who want to maximize computer skills and other information technology skills such as creating and using email. The results of this community service are: Participants understand, understand and take advantage of advances in the use of cellphones, create and use personal emails. This email can later be used to register for schools, either at the high school or college level. This activity was quite successful because there was an adequate internet network, which was given village Wi-Fi access.

Keywords: air anyir village, information technology capability, human resources improvement, email

Copyright (c) 2021 Lili Indah Sari, Wishnu Aribowo Probonegoro, Supardi, Parlia Romadiana

$\triangle$ Corresponding author

Address : ISB Atma Luhur

Email : lilie@atmaluhur.ac.id

DOI : https://doi.org/10.31004/abdidas.v2i3.322

ISSN 2721- 9224 (Media Cetak)

ISSN 2721- 9216 (Media Online)

Jurnal Abdidas Vol 2 No 3 Tahun 2021 p-ISSN 2721-9224 e-ISSN 2721-9216 
598 Peningkatan Kualitas SDM Melalui Pelatihan Penggunaan Teknologi Informasi di Desa Air Anyir -Lili Indah Sari, Wishnu Aribowo Probonegoro, Supardi, Parlia Romadiana

DOI: https://doi.org/10.31004/abdidas.v2i3.322

\section{PENDAHULUAN}

Kemampuan teknologi informasi saat ini yang begitu cepat dan berkembang dengan pesat menjadikan dunia ini begitu luas dan tanpa batas. Hampir semua informasi bisa kita dapatkan dengan mudah. Tidak hanya di perkotaan tetapi di desa-desa. Sehingga setiap peristiwa yang terjadi pada suatu daerah bahkan daerah terpencil pun atau negara dapat dengan mudah didengar atau dilihat (Purba, 2010). Kemampuan teknologi informasi yang dimiliki desa pastinya berbeda dengan yang ada di perkotaan. Desa Air Anyir merupakan salah satu desa yang berada di Kecamatan Merawang, Kabupaten Bangka, Provinsi Kepulauan Bangka Belitung. Desa Air Anyir ini merupakan desa pemekaran yang ada di Kabupaten Bangka. Rata-rata mata pencaharian warga desa ini yaitu berkebun, petani, bahkan ada beberapa yang menjadi nelayan. (Wikipedia, 2016) Masih rendahnya kesadaran dalam memiliki pendidikan dan pengembangan kualitas sumber daya manusia dalam hal ini adalah masyarakat yang ada di desa menyebabkan minimnya pendapatan masyarakat desa. Manajemen sumber daya manusia sebagai aset penting bagi lembaga perlu dipelihara dengan baik. Tujuan utama dari manajemen sumber daya manusia adalah menyiapkan dan mewujudkan sumber daya manusia yang berkualitas, dan mempunyai kompetensi (Nawawi, 2011).

Era big data adalah era dimana informasi/data tersedia secara masif, sangat cepat, beragam format dan dapat diakses dari mana saja dan kapan saja (dimana ada internet) (Cope \& Kalantzis, 2016). Manfaat intenet merupakan manfaat yang sangat besar dalam kehidupan remaja untuk meningkatkan pengetahuan serta menambah wawasan remaja tentang komunikasi yang baik secara langsung dan sudah terjalin dengan orang lain. Manfaat internet mampu memberikan banyak informasi yang dibutuhkan oleh setiap remaja dan dapat mempermudah komunikasi dari jarak yang sangat jauh tanpa harus dengan bertatap muka secara langsung (Talika, 2016).

Kehadiran teknologi digital di masyarakat telah memberikan dampak yang cukup signifikan terhadap pola perilaku kehidupan masyarakat perkotaan dan pedesaan. (Nugraha et al., 2019). Pemerintah berkeinginan membawa warga negaranya agar tidak tertinggal atau "left behind" dan bisa memenangkan atau "winning" era globalisasi yang terjadi (Selwyn, 2004). Sehingga desa memiliki wewenang dalam penyelenggaraan pemerintahan, pelaksanaan pembangunan, pembinaan kemasyarakatan, dan pemberdayaan masyarakat desa (Republik, 2014).

Kemampuan untuk menguasai teknologi informasi pada umumnya sebaiknya harus dimiliki oleh masyarakat desa, khususnya remaja yang ada di Desa Air Anyir. Dikarenakan kemajuan informasi dan teknologi menuntut adanya kewajiban pada penguasaaan ilmu di bidang teknologi informasi untuk menghadapi era globalisasi ini. Peningkatan kualitas Sumber Daya Manusia (SDM) sebaiknya dimulai sejak dini (tingkat remaja). Untuk meningkatkan SDM yang ada di Desa Air Anyir perlu dilakukannya kolaborasi dan kerja sama dari semua pihak. Baik itu pihak desa beserta jajarannya, masyarakat 
maupun dari akademisi, dalam hal ini perguruan tinggi. Tanpa adanya kolaborasi dan kerja sama, maka kualitas SDM yang diharapkan hanya sebuah impian belaka. Saat ini kepala desa beserta jajarannya sudah berusaha maksimal untuk meningkatkan SDM yang ada di desanya, dengan memberikan penyuluhan, sosialisasi bahkan pelatihan kepada masyarakat desa, khususnya para remajanya. Untuk itu, Institut Sains dan Bisnis Atma Luhur Pangkal Pinang, bekerja sama dengan pihak Desa Air Ainyir dan dukungan dari masyarakatnya mencoba membantu memberikan keterampilan komputer guna meningkatkan pengetahuan dan skil keterampilan komputer bagi masyarakat yang ada di Desa Air Anyir, khususnya para remaja.

\section{METODE}

Metode pelaksanaan kegiatan pengabdian kepada masyarakat adalah metode pelatihan. Maksud dari pelatihan ini yaitu pelatihan ini hanya dilakukan dalam 1 hari, yaitu dari pagi hingga sore hari. Pelatihan teknologi informasi ini terdiri dari ceramah, tanya jawab, praktik langsung.

Metode ceramah dan tanya jawab digunakan untuk memperkenalkan pengetahuan dan keterampilan yang diberikan. Metode ceramah diberikan ketika menyampaikan materi dan langkah-langkah yang dilakukan dalam penggunaan teknologi informasi dalam hal ini pembuatan dan penggunaan elektronik mail (email)/ surat elektronik. Tanya jawab untuk memperdalam materi yang sudah dijelaskan dalam ceramah. Tanya jawab juga berfungsi untuk mengetahui sejauh mana pemahaman peserta terhadap materi yang sudah diberikan. Praktik langsung yaitu dengan memberikan praktik langsung untuk mencoba dan membuat email masing-masing, bisa menggunakan handphone atau laptop.

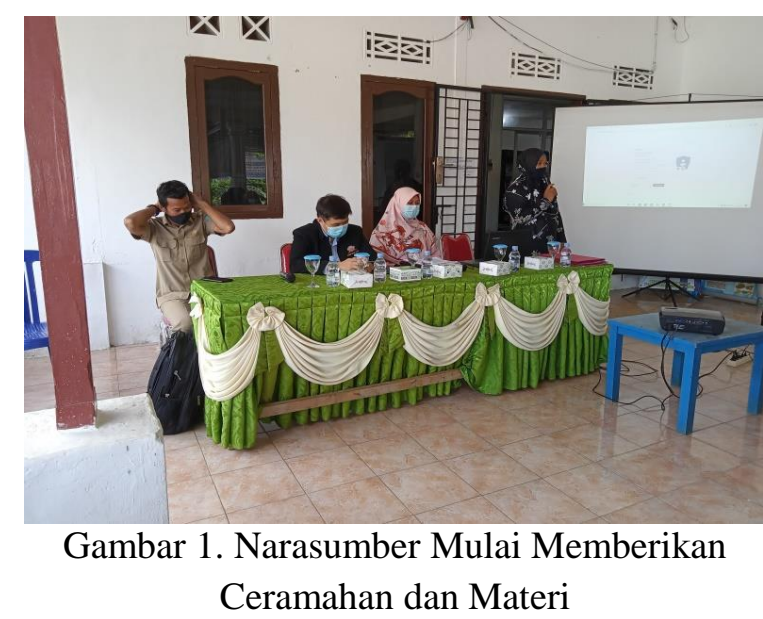

Ketiga metode ini digunakan secara bersamaan. Ketika narasumber memberikan ceramah dan langsung mempraktikkan bagaimana caranya, peserta boleh langsung menanyakan jika ada kesulitan dalam mempraktikkannya. Pada saat mengimplementasikan ilmu yang diajarkan oleh narasumber, peserta yang mengalami kesulitan dalam pelatihan ini juga dibantu oleh rekan-rekan mahasiswa dari ISB Atma Luhur

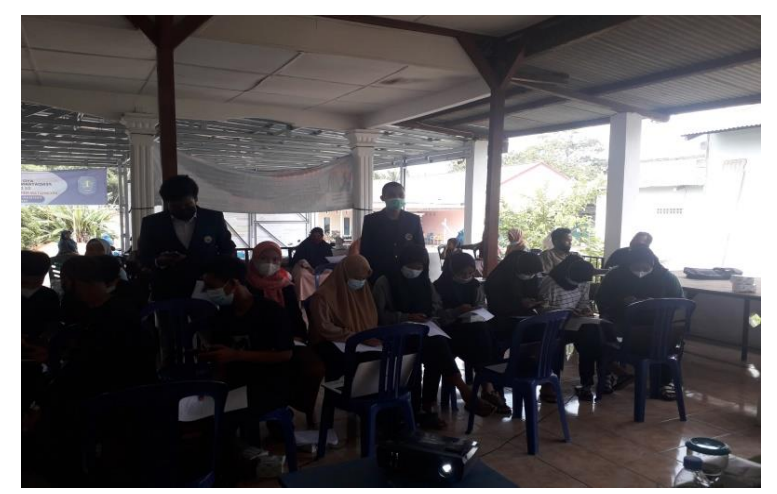

Gambar 2. Suasana Antusias Para Peserta Mengikuti Kegiatan 
600 Peningkatan Kualitas SDM Melalui Pelatihan Penggunaan Teknologi Informasi di Desa Air Anyir -Lili Indah Sari, Wishnu Aribowo Probonegoro, Supardi, Parlia Romadiana

DOI: https://doi.org/10.31004/abdidas.v2i3.322

Narasumber dalam pengabdian masyarakat ini adalah para dosen dari ISB Atma Luhur Pangkal Pinang, dibantu dengan beberapa mahasiswa guna memberikan kemudahan dalam pemberian pelatihan kemampuan teknologi informasi. Sedangkan khalayak sasaran adalah warga Desa Air Anyir, khususnya tingkat remaja yang ingin memaksimalkan kemampuan komputer yang ada dengan cara mengoperasionalkan komputer dengan lebih baik serta kemampuan teknologi informasi yang lain seperti pembuatan email. Pembuatan email bisa menggunakan laptop atau handphone/gadget dari masing masing peserta yang mengikuti pelatihan ini.

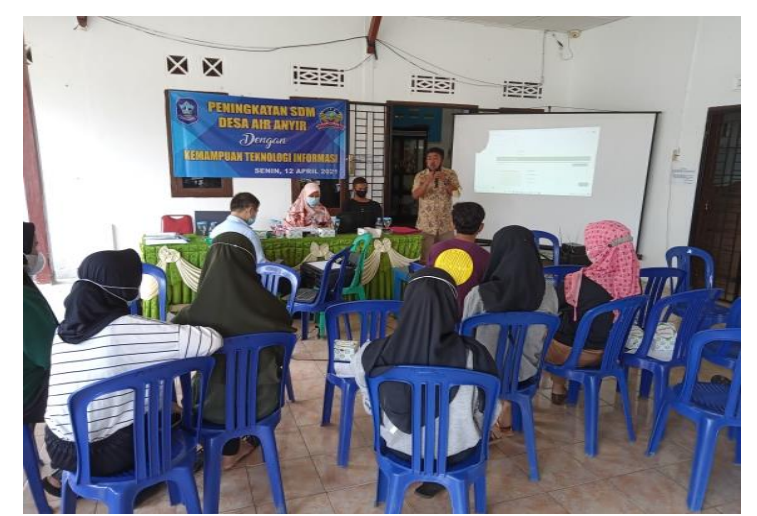

Gambar 3. Pemateri Memberikan Jawaban dari Peserta yang Bertanya

Setelah pelatihan ini, para remaja ini di haruskan untuk membuat dan sudah mempunyai email masing-masing. Dimana mereka juga harus mengingat login dan password dari email yang sudah dibuat. Sebagai evaluasi akhir dan latihan bahwa mereka sudah bisa menggunakan email, mereka harus mengirimkan minimal 1 email kepada narasumber dan staff desa yang bertanggung jawab terhadap pelatihan ini.
Selain itu penulis dan penanggung jawab kegiatan ini juga membuat laporan pengabdian masyarakat ini. Penulis melaporkan kegiatan ini kepada Ketua LPPM ISB Atma Luhur, sedangkan penanggungjawab kegiatan desa ( staff desa) melaporkan kegiatan ini kepada Kepala Desa Air Anyir.

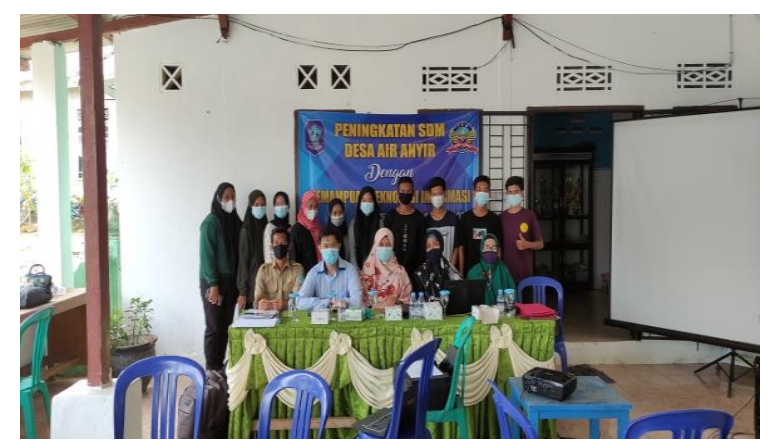

Gambar 4. Foto Bersama dengan Narasumber, Perangkat Desa dan Peserta

\section{HASIL DAN PEMBAHASAN}

Adapun hasil dari kegiatan pengabdian masyarakat yang dilakukan penulis dengan judul "Peningkatan Sumber Daya Manusia ( SDM) Desa Air Anyir dengan Kemampuan Teknologi Informasi," dengan melalui dua tahapan yaitu a. Tahap Persiapan

Tahap persiapan dilakukan dengan cara melakukan survei dan wawancara kepada kepala desa yang diwakili kepada sekretaris desa terhadap kebutuhan teknologi informasi yang diperlukan untuk remaja desa. Setelah berdiskusi dan wawancara penulis dan sekretaris desa membuat jadwal yan tepat untuk melakukan pelatihan singkat tentang teknologi informasi, khususnya dalam pembuatan dan penggunaan email. Pihak desa juga mencari beberapa remaja yang mau ikut pelatihan. 
601 Peningkatan Kualitas SDM Melalui Pelatihan Penggunaan Teknologi Informasi di Desa Air Anyir -Lili Indah Sari, Wishnu Aribowo Probonegoro, Supardi, Parlia Romadiana

DOI: https://doi.org/10.31004/abdidas.v2i3.322

\section{b. Tahap pelaksanaan}

Pada tahap pelaksanaan ini Desa Air Anyir beserta masyarakatnya memberikan dukungan yang luar biasa terhadap pelatihan teknologi informasi ini. Dukungan yang diberikan desa diantaranya; menyediakan dan menjadikan kator desa sebagai tempat pelaksanaan kegiatan pelatihan ini, menyiapkan peserta, menyediakan infocus, menyediakan internet dalam hal ini Wi-Fi desa bisa digunakan untuk pelatihan ini.

Kegiatan pengabdian masyarakat ini dilaksanakan hanya satu hari yaitu pada tanggal 12 April 2021 di Kantor Desa Air Anyir. Pelatihan singkat pembuatan dan penggunaan email ini kepada remaja Desa Air Anyir diharapkan membawa perubahan terhadap kemampuan remaja dalam kemajuan teknologi informasi, dikarenakan pemanfataan internet menjadi salah satu faktor yang sangat penting di era globalisasi ini . Peserta memahami, mengerti dan tahu bagaimana memanfaatkan kemajuan teknlogi informasi dalam hal ini pemanfaatan handphone untuk membuat dan menggunakan email pribadi. Karena email ini nantinya bisa digunakan untuk mendaftar sekolah baik di tingkat SMA ataupun tingkat perguruan tinggi. Kegiatan ini cukup berhasil karena adanya jaringan internet yang memadai, yaitu diberikan akses Wi-Fi desa pada saat pelatihan ini, walaupun terkadang sedikit kendala dengan sinyal jaringan walaupun pelatihan ini hanya 1 hari, penulis membuatkan grup WhatsApp agar bisa selalu berkomunikasi dan berdiskusi baik kepada para peserta, perangkat desa yang mau bertanya dan kesulitan dalam penggunaan teknologi informasi, atau ada kendala dengan emailnya. c. Tahap Evaluasi dan capaian Kegiatan

Peserta yang sudah bisa membuat dan sering menggunakan email sekitar $30 \%$ dari jumlah peserta yang ikut pelatihan ini. Peserta juga diharuskan sudah mempunyai email masing masing dengan mengingat login dan password yang sudah dibuatnya. Untuk mengecek atau mengevaluasi para peserta ini, peserta harus mengirimkan satu email kepada narasumber dan staff desa yang bertanggung jawab terhadap kegiatan ini.

Setelah kegiatan ini mempunyai dampak positif dan manfaat yang luar biasa, baik bagi peserta, masyarakat maupun desa. Salah satu manfaat kegiatan ini yaitu bisa meningkatkan SDM remaja desa dalam melakukan pendaftaran sekolah secara online. Serta bisa berbagi pengetahuan ini dengan remaja lain yang tidak bisa mengikuti kegiatan ini. Pihak desa meminta penulis dan tim agar bisa melakukan kegiatan pelatihan teknologi informasi yang lainnya di Desa Air Anyir ini.

\section{SIMPULAN}

Dari hasil kegiatan pengabdian kepada masyarakat yang dilakukan di Desa Air Anyir ini dapat disimpulkan bahwa:

1. Dengan adanya pelatihan pembuatan dan penggunaan email ini diharapkan dapat meningktakan kualitas sumber daya manusia dengan kemampuan teknologi informasi.

2. Adanya dukungan dan kerjasama dari semua pihak yaitu pihak desa dan perangkat desa, masyarakat, perguruan tinggi. 
602 Peningkatan Kualitas SDM Melalui Pelatihan Penggunaan Teknologi Informasi di Desa Air Anyir -Lili Indah Sari, Wishnu Aribowo Probonegoro, Supardi, Parlia Romadiana

DOI: https://doi.org/10.31004/abdidas.v2i3.322

Kegiatan pelatihan Teknologi informasi ini, masih merupakan tahap awal, sebaikanya pihak desa juga mengadakan pelatihan IT berkelanjutan atau pelatihan IT yang lain, baik untuk para remaja, perangkat desa ataupun masyarakat guna untuk meningkatkan kualiatas SDM yang ada di desa Air Anyir.

\section{UCAPAN TERIMA KASIH}

Pelaksanaan kegiatan pengabdian masyarakat ini tidak terlepas dari bantuan dan dukungan dari beberapa pihak. Oleh karena itu, penulis ingin mengucapkan terima kasih kepada

1. Lembaga Penelitian dan Pengabdian Masyarakat (LPPM) ISB Atma Luhur dan Yayasan Atma Luhur yang selalu memberikan dukungan, baik dalam bentuk material, finansial maupun spiritual.

2. Kepala desa, sekretaris desa, perangkat desa, dan semua lapisan masyarakat Desa Air Anyir yang sudah bersedia bekerjasama dalam melakukan pengabdian masyarakat ini.

3. Semua pihak yang turut membantu terlaksananya pengabdian masyarakat ini.

\section{DAFTAR PUSTAKA}

Cope, B., \& Kalantzis, M. (2016). Big Data Comes to school: Implications for Learning, Assessment, and Research. AERA Open April-Juni 2016, 2(2), 1-19. https://doi.org/DOI: $10.1177 / 2332858416641907$

Nawawi, H. (2011). Manajemen Sumber Daya Manusia untuk bisnis yang kompetitif (delapan). Gadjah Mada University Press.

Nugraha, A. R., Novianti, E., Komala, L.,
Lukman, S., \& Sjoraida, D. F. (2019). Pelatihan Media Online Dalam Upaya Meningkatkan Melek Informasi Kalangan Milineal pada Program Pembangunan di Desa Purbahayu. JPM (Jurnal Pemberdayaan Masyarakat), 4(2), 314-321. https://doi.org/10.21067/jpm.v4i2.3549

Purba, S. (2010). Peningkatan Kualitas Sumber Daya Manusia Melalui Sektor Pendidikan. Generasi Kampus, 3(1).

Republik, I. (2014). Undang Undang Republik Indonesia Nomor 6 Tahun 2014 Tentang Desa.

https://doi.org/10.1145/2904081.2904088

Selwyn, N. (2004). Reconsidering Political and Popular Understanding of the Digital Divide: in New Media \& Society. Sage Publication, 6(3), 341-362.

Talika, F. T. (2016). Manfaat Internet Sebagai Media Komunikasi Bagi Remaja Di Desa Air Mangga Kecamatan Laiwui Kabupaten Halmahera Selatan. E-Journal, 5(1), 1-6. https://ejournal.unsrat.ac.id/index.php/actadiu rnakomunikasi/article/view/10933/10522

Wikipedia. (2016). No Title. Wikipedia Ensiklopedia Bebas. https://id.wikipedia.org/wiki/Air_Anyir,_Mer awang,_Bangka 